\title{
A Universal Strategy To Prepare Sulfur-Containing Polymer Composites with Desired Morphologies for Lithium-Sulfur Batteries
}

\author{
Shao-Zhong Zeng, ${ }^{\dagger}$, Xierong Zeng, ${ }^{\dagger}$, Wenxuan Tu, ${ }^{\dagger}$ Haitao Huang, ${ }^{\S}$ Liang Yu, ${ }^{\dagger}$ Yuechao Yao, ${ }^{\dagger}$ \\ Nengzhi Jin, "Qi Zhang, ${ }^{\perp}$ and Jizhao Zou ${ }^{*}, \dagger, \#$ \\ ${ }^{\dagger}$ Shenzhen Key Laboratory of Special Functional Materials \& Shenzhen Engineering Laboratory for Advance Technology of \\ Ceramics, College of Materials Science and Engineering, and Key Laboratory of Optoelectronic Devices and Systems of Ministry of \\ Education and Guangdong Province, College of Optoelectronic Engineering, Shenzhen University, Shenzhen 518060, P. R. China \\ sDepartment of Applied Physics, The Hong Kong Polytechnic University, Hung Hom, Kowloon, Hong Kong 999077, P. R. China \\ "Gansu Computing Center, Lanzhou 730030 Gansu, China \\ ${ }^{\perp}$ Department of Manufacturing and Materials, Cranfield University, Cranfield, Bedfordshire MK43 0AL, U.K. \\ \#Guangdong JANUS Intelligent Group Corporation Limited, Dongguan 523878, China \\ * supporting Information
}

ABSTRACT: Lithium-sulfur ( $\mathrm{Li}-\mathrm{S})$ batteries are probably the most promising candidates for the next-generation batteries owing to their high energy density. However, $\mathrm{Li}-\mathrm{S}$ batteries face severe technical problems where the dissolution of intermediate polysulfides is the biggest problem because it leads to the degradation of the cathode and the lithium anode, and finally the fast capacity decay. Compared with the composites of elemental sulfur and other matrices, sulfur-containing polymers (SCPs) have strong chemical bonds to sulfur and therefore show low dissolution of polysulfides. Unfortunately, most SCPs have very low electron conductivity and their morphologies can hardly be controlled, which undoubtedly depress the battery performances of SCPs. To overcome these two weaknesses of SCPs, a new strategy was developed for preparing SCP composites with enhanced conductivity and desired morphologies. With this strategy, macroporous SCP composites were successfully prepared from hierarchical

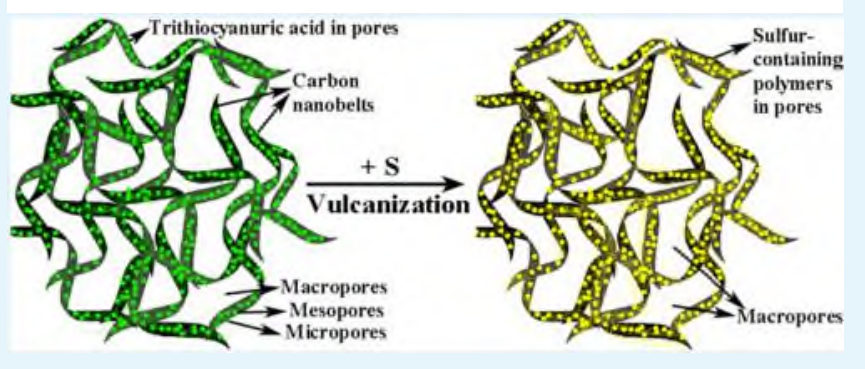
porous carbon. The composites displayed discharge/charge capacities up to $1218 / 1139,949 / 922$, and $796 / 785 \mathrm{~mA} \mathrm{~h} \mathrm{~g}^{-1}$ at the current rates of 5,10 , and $15 \mathrm{C}$, respectively. Considering the universality of this strategy and the numerous morphologies of carbon materials, this strategy opens many opportunities for making carbon/SCP composites with novel morphologies.

KEYWORDS: lithium batteries, sulfur-containing polymers, morphological control, porous carbon nanobelts, carbon/sulfur composites

\section{INTRODUCTION}

Rechargeable lithium-sulfur ( $\mathrm{Li}-\mathrm{S})$ batteries display unparalleled energy density $\left(2600 \mathrm{~W} \mathrm{~h} \mathrm{~kg}^{-1), 1,2}\right.$ low cost, and environmental friendliness. ${ }^{2}$ However, the commercial production of $\mathrm{Li}-\mathrm{S}$ batteries is blocked by several problems, including (a) the dissolution and diffusion of lithium polysulfides (LiPSs) in the ether liquid electrolyte, ${ }^{1,2}$ which results in the loss of sulfur and capacity decay, (b) the large volumetric change $(80 \%)$ during the charge/discharge processes, ${ }^{2}$ which causes the degradation of the electrode, and (c) the inherent poor electronic/ionic conductivity of sulfur and its intermediate/end products of discharge, ${ }^{2}$ which blocks the migration of electron and lithium ion during the charge-discharge reactions. Various methods have been tried to resolve these challenges, including physically encapsulating sulfur in porous carbon materials or other porous matrices,3-19 chemically bonding sulfur to polymer matrices, ${ }^{20-33}$ constructing LiPS-blocking interlayers, ${ }^{34-39}$ applying functional binders, and developing all-solid-state $\mathrm{Li}-\mathrm{S}$ batteries. ${ }^{40-45}$ Among these methods, one of the most popular approaches is composing sulfur with carbonaceous materials because of their electronic conductivity and adjustabilities in surface area, porosity, and nanostructures. ${ }^{2,5,46}$ However, these composites could not effectively hinder the loss of LiPSs owing to the weak interactions between the nonpolar carbon and polar LiPSs. ${ }^{1}$ To reinforce the interactions, heteroatom doping, ${ }^{47,48}$ surface functionalization, and pore size tailoring are widely used for modifying carbonaceous materials.49-53

Another approach to improve the loss of LiPSs is to chemically bond sulfur on the matrices. The reported matrices include polyacrylonitrile, ${ }^{22}$ 1,3-diisopropenylbenzene,20,21,25,28 covalent triazine framework, ${ }^{24}$ polyaniline nanotubes, ${ }^{23}$ trithiocyanuric acid (TTCA), ${ }^{29,31}$ poly(1,3-diethynylbenzene), and carbyne analogue. ${ }^{26,54}$ These sulfur-containing polymers 
(SCPs) display better performances as compared with the carbon/sulfur composites. However, the low conductivity of most SCPs and the difficulties in controlling their morphologies definitely depress their performances in the $\mathrm{Li}-\mathrm{S}$ batteries. ${ }^{25,29,31,55}$ Only a few articles reported the methods for enhancing the conductivity, meanwhile controlling the morphologies of SCPs.21,25,31

To improve these two disadvantages of SCP, a stepwise strategy for preparing a composite of hollow carbon spheres (HCSs) and SCP has been developed. ${ }^{31}$ With this strategy, the SCP has been encapsulated within the micro- and mesopores of spherical shells, resulting in a hollow spherical structure that is just the same as that of HCSs. ${ }^{31}$ The HCSs in this composite act not only as conductive agents but also as templates. ${ }^{31}$ Because this strategy is universal to most carbon materials, ${ }^{31}$ it has the potential to be a universal method that could tailor the morphologies of the carbon/SCP composites by tailoring the morphologies of the carbon materials. As a proof of concept to confirm the universality of this strategy, clews of carbon nanobelts (CsCNBs) were chosen as templates and conductive agents in this work. ${ }^{13} \mathrm{CsCNBs}$ are hierarchically porous carbon materials with micro-, meso-, and macropores. The macropores of $\mathrm{CsCNBs}$ come from the original clews of polymer nanobelts (CsPNBs), whereas the micro- and mesopores are formed during the carbonizing and activating processes. ${ }^{13,56}$

With this strategy, a composite of CsCNBs-SCP was successfully synthesized. This composite retains the macroporous structure of CsCNBs. Owing to the combination of the advantages of SCP and the hierarchically porous structure of CsCNBs, the composite shows a fast charge-discharge capability with the current rate up to $15 \mathrm{C}\left(1 \mathrm{C}=1670 \mathrm{~mA} \mathrm{~g}^{-1}\right)$. The discharge/charge capacities up to $1218 / 1139,949 / 922$, and $796 / 785 \mathrm{~mA} \mathrm{~h} \mathrm{~g}^{-1}$ can be achieved at the current rates of 5, 10, and $15 \mathrm{C}$, respectively. More importantly, this work has confirmed the universality and effectiveness of this strategy in which more morphological composites from other morphological carbons, such as nanofibers, ${ }^{16}$ nanotubes,,${ }^{7,21}$ twodimensional sheets, and so forth, ${ }^{25}$ are worthy of studying in the future. In this work, the tailoring of the morphologies of SCPs is simplified to the tailoring of the morphologies of carbon materials, which provides a lot of opportunities for making carbon/SCP composites with novel morphologies.

\section{EXPERIMENTAL SECTION}

2.1. Materials. Hydroquinone [Analytical Reagent (AR), 99\%], formaldehyde (AR, $37 \mathrm{wt} \%$ ), concentrated hydrochloric acid (AR, 37 wt \%), sulfur (AR, 99.9\%), CS $(\mathrm{AR})$, and tetrahydrofuran (THF, AR) were purchased from Shanghai Macklin Company (P. R. China).

2.2. Preparations of CsPNBs, CsCNBs, and CsCNBs-S. $\mathrm{CsPNBs}$, CsCNBs, and $\mathrm{CsCNBs}-\mathrm{S}$ were synthesized according to refs ${ }^{13,56}$ The activation time of CsCNBs was $40 \mathrm{~min}$. The sulfur content in $\mathrm{CsCNBs}-\mathrm{S}$ was set to be $80 \%$.

2.3. Preparation of CsCNBs-SCP70S Composites. CsCNBs of $0.10 \mathrm{~g}$ and TTCA of $0.10 \mathrm{~g}$ were dissolved in $2 \mathrm{~mL}$ of THF and stirred till drying completely. Then, $0.40 \mathrm{~g}$ of sulfur and $3 \mathrm{~mL}$ of $\mathrm{CS}_{2}$ were added to the composite of CsCNB-TTCA and stirred till drying completely. The product was heated $\left(5^{\circ} \mathrm{C} \mathrm{min}-1\right)$ to $200{ }^{\circ} \mathrm{C}$ in a tube furnace, and held at $200{ }^{\circ} \mathrm{C}$ for $4 \mathrm{~h}$, followed by further heating $\left(5^{\circ} \mathrm{C}\right.$ $\mathrm{min}^{-1}$ ) to $250{ }^{\circ} \mathrm{C}$ for $2 \mathrm{~h}$. Accordingly, CsCNB-SCP35S was prepared by decreasing the dosage of TTCA and sulfur $(0.12 \mathrm{~g}$ CsCNBs, $0.024 \mathrm{~g}$ TTCA, and $0.08 \mathrm{~g}$ sulfur).

2.4. Characterizations. Powder X-ray diffraction (XRD), nitrogen isotherms, scanning electron microscopy (SEM), energy-dispersive spectroscopy (EDS), transmission electron microscopy (TEM), Raman analysis, thermogravimetric (TG) analysis, and X-ray photoelectron spectroscopy (XPS) experiments were performed according to refs. . $^{13,31}$

2.5. Cell Fabrication and Measurements. To evaluate the battery performances of $\mathrm{CsCNBs}-\mathrm{S}$ and $\mathrm{CsCNBs}-\mathrm{SCP}, \mathrm{CR} 2016$ cells were fabricated according to the methods reported elsewhere. ${ }^{31}$ The sulfur loading of $\mathrm{CsCNBs}^{-\mathrm{S}}$ and $\mathrm{CsCNBs}-\mathrm{SCP} 70 \mathrm{~S}$ was $1.5-2.0 \mathrm{mg}$ $\mathrm{cm}^{-2}$. For CsCNBs-TTCA-35S, the sulfur loading was $\sim 0.5 \mathrm{mg} \mathrm{cm}^{-2}$. The cyclic voltammetry (CV) measurements, electrochemical impedance spectra (EIS) measurement, and charge-discharge cycling were conducted according to ref 31 .

2.6. Computational Method. All theoretical calculations were performed by using Gaussian 09. All models were optimized by B3LYP/6-31+G(d) to gain the most stable configurations. The Gibbs free energies of all optimized configurations were calculated by B3LYP/6-311+G(2df). According to ref 57, the calculation based on gas phase does not affect the accuracy of the Gibbs free-energy changes. Except where noted, the gas-phase Gibbs free energy was used in the whole work.

\section{RESULTS AND DISCUSSION}

The new strategy for preparing SCP composites with desired morphologies involves three steps (Figure 1). First, a porous

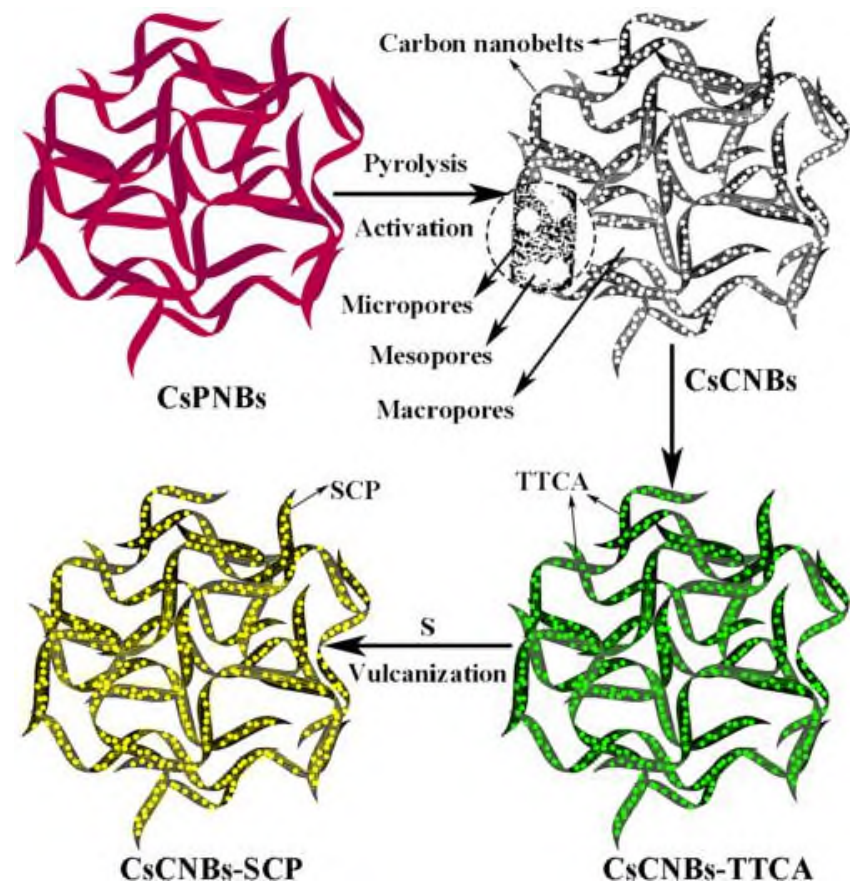

Figure 1. Schematic illustrations of $\mathrm{CsCNBs}, \mathrm{CsCNBs}^{-T T C A}$, and CsCNBs-SCP.

carbon with a desired morphology is selected as the template and conductive agent. Second, a vulcanizater that can crosslink the sulfur molecules to form an SCP is loaded within the porous carbon material, and a composite is formed. Third, this composite is further mixed with sulfur, and the resulted mixture is then vulcanized at a higher temperature to form a composite of carbon and SCP. The morphology of the porous carbon material determines the morphology of the final composite.

Accordingly, TTCA is chosen as a vulcanizater because it can cross-link the sulfur molecules and it is a soluble solid. ${ }^{29}$ The solubility of TTCA enables its loading into the pores of carbon by a dipping method. The high melting point $\left(\geq 300{ }^{\circ} \mathrm{C}\right)$ of TTCA prevents it from streaming out of the pores during the drying and vulcanization processes at high 
temperature. Moreover, TTCA has a high nitrogen content that catalyzes the charge-discharge reaction and depresses the dissolution of LiPSs by providing more anchoring sites.

Figure S1 displays the SEM images of CsCNBs and their composites. Obviously, the clew structure and the macropores of CsCNBs are retained after loading with TTCA, SCP, and sulfur. Figure 2 displays the high-resolution SEM images of
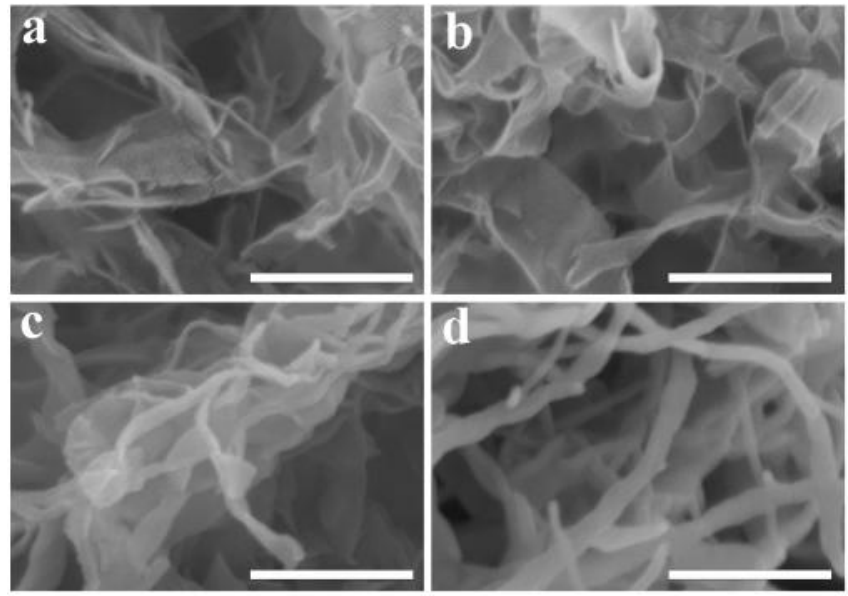

Figure 2. SEM images of (a) $\mathrm{CsCNBs,} \mathrm{(b)} \mathrm{CsCNBs}^{-T T C A}$, (c)

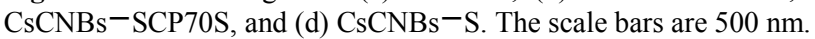

CsCNBs and their composites. The pores in the carbon nanobelts (CNBs) are visible in Figure 2a. After loading with TTCA, the pores (Figure 2b) become indistinct and the thickness of the CNBs displays no obvious changes, which demonstrate that TTCA is encapsulated within the micro- and mesopores in the CNBs. Compared with CsCNBs-TTCA, the CNBs of $\mathrm{CsCNBs}^{-} \mathrm{SCP} 70 \mathrm{~S}$ (Figure 2c) and $\mathrm{CsCNBs}^{-\mathrm{S}}$
(Figure 2d) show a slightly increased thickness because a part of SCP or sulfur coats on the CNBs.

The TEM images of CsCNBs, CsCNBs-TTCA, and CsCNBs-SCP70S are shown in Figure 3. The TEM images with low magnification (Figure 3a,d,g) confirm that the nanobelt structure of $\mathrm{CsCNBs}$ is retained and that there are no particles of TTCA and SCP outside the nanobelts of CsCNBs-TTCA and $\mathrm{CsCNBs}-\mathrm{SCP} 70 \mathrm{~S}$, respectively. Numerous mesopores are clearly visible in the TEM images of CsCNBs and CsCNBs-TTCA (Figure 3b,e), which become indistinct in the

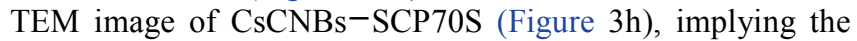
filling of the mesopores by the SCP. The high-resolution TEM (HRTEM) image of CsCNBs (Figure 3c) shows no lattice fringes of graphitic carbon, indicating that the $\mathrm{CsCNBs}$ possess a highly disordered structure. There are also no lattice fringes of TTCA in the HRTEM image of CsCNBs-TTCA (Figure 3f), which demonstrates that TTCA exists in an amorphous state. The HRTEM image of CsCNBs-SCP70S (Figure 3i) confirms that SCP exists in an amorphous state. The carbon, sulfur, nitrogen, and oxygen mappings of CSCNBs-SCP70S (Figure 3j) display similar patterns, demonstrating the homogeneous distribution of these elements.

Figure 4a shows the Fourier transform infrared (FTIR) spectra of CsCNBs, TTCA, CsCNBs-TTCA, and CsCNBs- SCP70S. The spectrum of CsCNBs displays a broad peak at 900-1300 $\mathrm{cm}^{-1}$, which corresponds to the vibrations of $\mathrm{C}-\mathrm{H}$ and $\mathrm{C}-\mathrm{O}$. Owing to the weak FTIR characteristic peaks of CsCNBs, the spectrum of CsCNBs-TTCA should mainly reflect the characteristic peaks of TTCA. However, the spectrum of CsCNBs-TTCA is different from that of TTCA. The spectrum of TTCA shows $\mathrm{N}-\mathrm{H}$ in-plane bending vibrations at $\sim 1750$ $\mathrm{cm}^{-1}$. This band is intensified in the spectrum of CsCNBs-TTCA, which indicates that the intermolecular hydrogen bonds of TTCA are weakened and

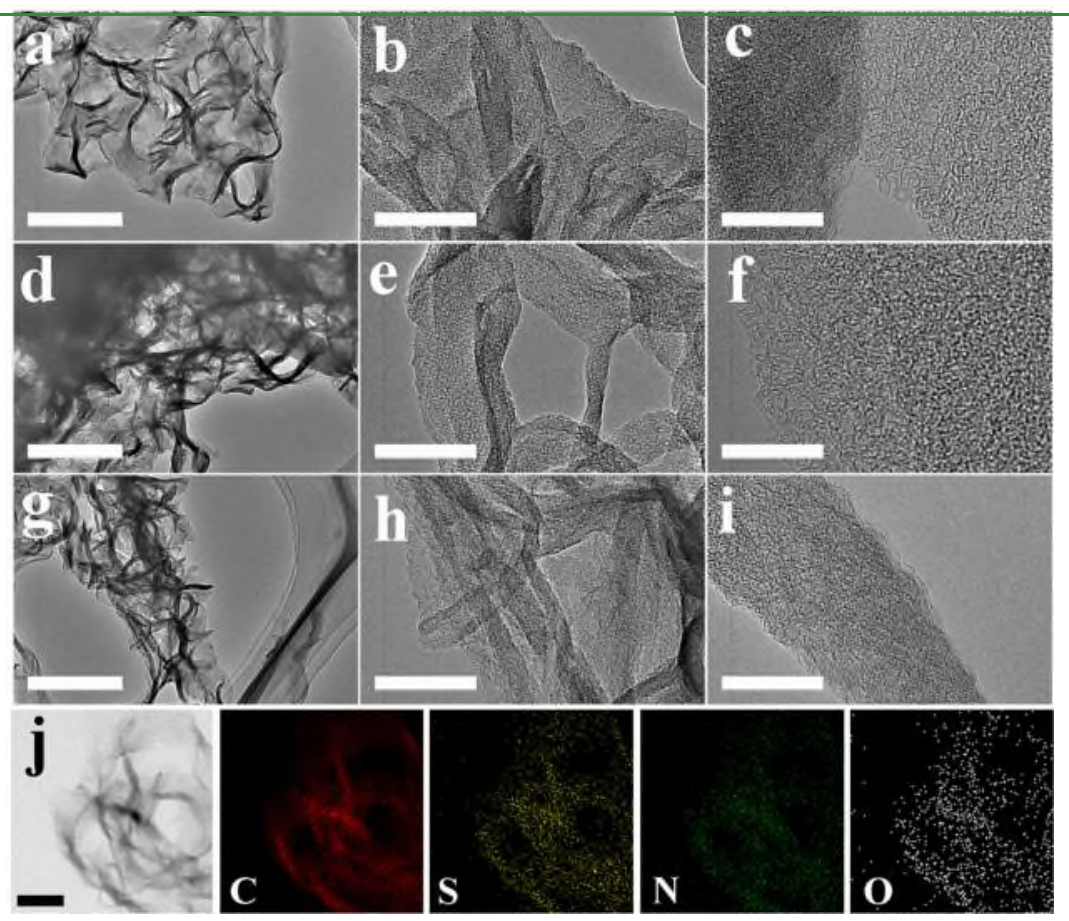

Figure 3. TEM images of $(a-c)$ CsCNBs, $(d-f) C s C N B s-T T C A$, and $(g-i)$ CsCNBs-SCP; (j) TEM image and elemental mappings of CsCNBs - SCP. In $(a-i)$, the scale bars from left to right are 500, 100, and $20 \mathrm{~nm}$, respectively. The scale bar in (j) is $200 \mathrm{~nm}$. 

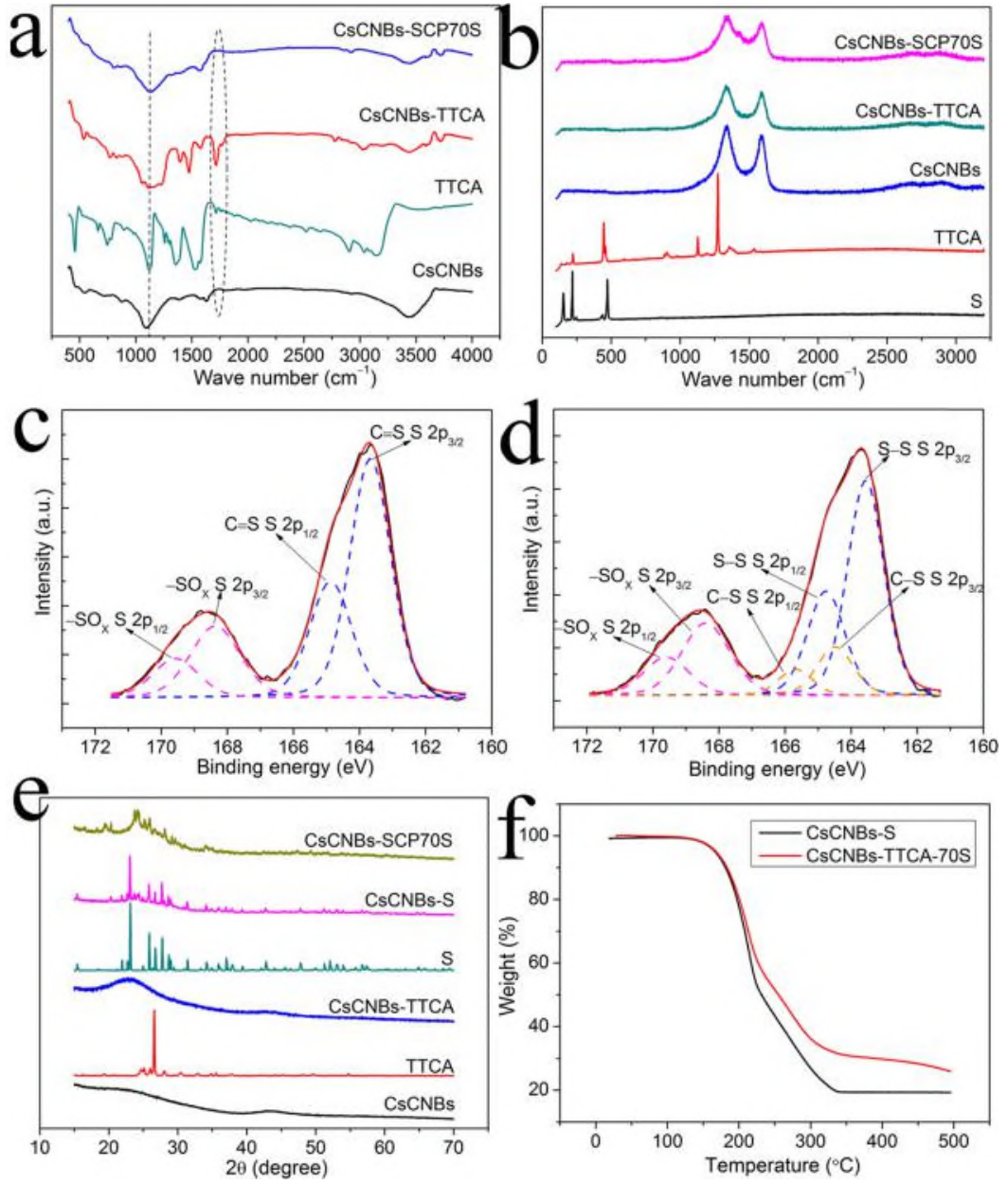

Figure 4. (a) FTIR spectra. (b) Raman spectra. S 2p XPS spectra of (c) CsCNBs-TTCA and (d) CsCNBs-SCP70S. (e) XRD patterns. (f) TG curves of $\mathrm{CsCNBs}^{-} \mathrm{S}$ and $\mathrm{CsCNBs}-\mathrm{SCP} 70 \mathrm{~S}$.

that TTCA is highly dispersed in CsCNBs. The strong peaks at $1120 \mathrm{~cm}^{-1}$ (C=S stretching vibrations) and $\sim 1750 \mathrm{~cm}^{-1}(\mathrm{~N}-$ $\mathrm{H}$ in-plane bending vibrations) in the spectrum of $\mathrm{CsCNBs}^{-}$ TTCA are weakened or disappeared in the spectrum of CsCNBs-TTCA-70S, ${ }^{31,58}$ which indicates that the vulcanization degree is very high. The Raman spectrum of CsCNBs (Figure $4 \mathrm{~b}$ ) displays the characteristic peaks of amorphous carbon. ${ }^{13}$ The Raman spectra of $\mathrm{CsCNBs}-\mathrm{TTCA}$ and CsCNBs-SCP70S (Figure 4b) are similar to those of CsCNBs and show no characteristic peaks of TTCA and sulfur. This confirms that SCPs are formed and encapsulated in the microand mesopores of CsCNBs, which coincides with the results of SEM (Figure 2) and the EDS mappings (Figure 3j).

The chemical states of sulfur were further monitored by XPS. The S $2 p$ XPS spectrum of CsCNBs-TTCA (Figure 4c) has two couples of peaks at 163.7/164.9 and 168.4/169.6 eV, corresponding to the sulfur of $\mathrm{C}=\mathrm{S}$ and $-\mathrm{SO}_{x},{ }^{46}$ whereas the $\mathrm{S}$ $2 \mathrm{p}$ XPS spectrum of CsCNBs-SCP70S (Figure 4d) displays three couples of peaks at 163.6/164.8, 164.5/165.7, and 168.4/ $169.6 \mathrm{eV}$, corresponding to the sulfur of $\mathrm{S}-\mathrm{S}, \mathrm{C}-\mathrm{S}$ and $-\mathrm{SO}_{x}$, respectively. This confirms that the $\mathrm{C}=\mathrm{S}$ bonds of TTCA have been converted into $\mathrm{C}-\mathrm{S}$ bonds and $\mathrm{S}-\mathrm{S}$ bonds in CsCNBs-SCP70S.

The powder XRD patterns are shown in Figure 4e. The XRD pattern of $\mathrm{CsCNBs}$ demonstrates their amorphous structure. Owing to the micro- and mesopores that inhibit the crystallization of TTCA, the characteristic peaks of TTCA do not appear in the XRD pattern of $\mathrm{CsCNBs}^{-T T C A}$. Because of the high sulfur content, the peaks of crystalline sulfur appear in $\mathrm{CsCNBs}^{-} \mathrm{S}$ and $\mathrm{CsCNBs}-\mathrm{SCP} 70 \mathrm{~S}$, implying that some sulfur was crystallized outside the CNBs. This is in agreement with the SEM images (Figure 2). The sulfur peaks in the pattern of $\mathrm{CsCNBs}-\mathrm{SCP} 70 \mathrm{~S}$ are significantly weaker than those in $\mathrm{CsCNBs}-\mathrm{S}$, indicating that there is less crystalline sulfur in CsCNBs-SCP70S.

Figure $4 \mathrm{f}$ shows the $\mathrm{TG}$ curves of $\mathrm{CsCNBs}-\mathrm{S}$ and $\mathrm{CsCNBs}-\mathrm{SCP} 70 \mathrm{~S}$. The sulfur content in $\mathrm{CsCNBs}^{-} \mathrm{S}$ was 80.6 wt $\%$. Because the loss of sulfur is accompanied with the loss of TTCA, the sulfur content in $\mathrm{CsCNBs}^{-} \mathrm{SCP} 70 \mathrm{~S}$ could not be estimated from the TG curve. Alternatively, the sulfur content

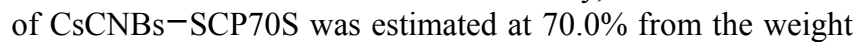
changes during vulcanization, which is consistent with the results of the elemental analysis $(\mathrm{C}, 20.6 \% ; \mathrm{N}, 4.81 \%$; $\mathrm{H}$, $0.131 \%$; and S, $72.723 \%$ ).

The electrochemical performance was first investigated by $\mathrm{CV}$ measurements. Figure 5a shows the $\mathrm{CV}$ curves. Both $\mathrm{CsCNBs}-\mathrm{SCP} 70 \mathrm{~S}$ and $\mathrm{CsCNBs}-\mathrm{S}$ show two cathodic peaks and one anodic peak at $0.05 \mathrm{mV} \mathrm{s}^{-1}$. When the sweep rate increases to $0.1 \mathrm{mV} \mathrm{s}^{-1}$, the cathodic peak at $1.9 \mathrm{~V}$ disappears in the $\mathrm{CV}$ curve of $\mathrm{CsCNBs}-\mathrm{S}$ and shifts to a lower voltage in the $\mathrm{CV}$ curve of $\mathrm{CsCNBs}-\mathrm{SCP} 70 \mathrm{~S}$. This indicates that the lithiumion diffusion coefficient of this reaction is lower in $\mathrm{CsCNBs}-\mathrm{S}$ than in $\mathrm{CsCNBs}-\mathrm{SCP} 70 \mathrm{~S}$. The lithium-ion diffusion coefficients $(D \mathrm{Li})$ were calculated from the peak 

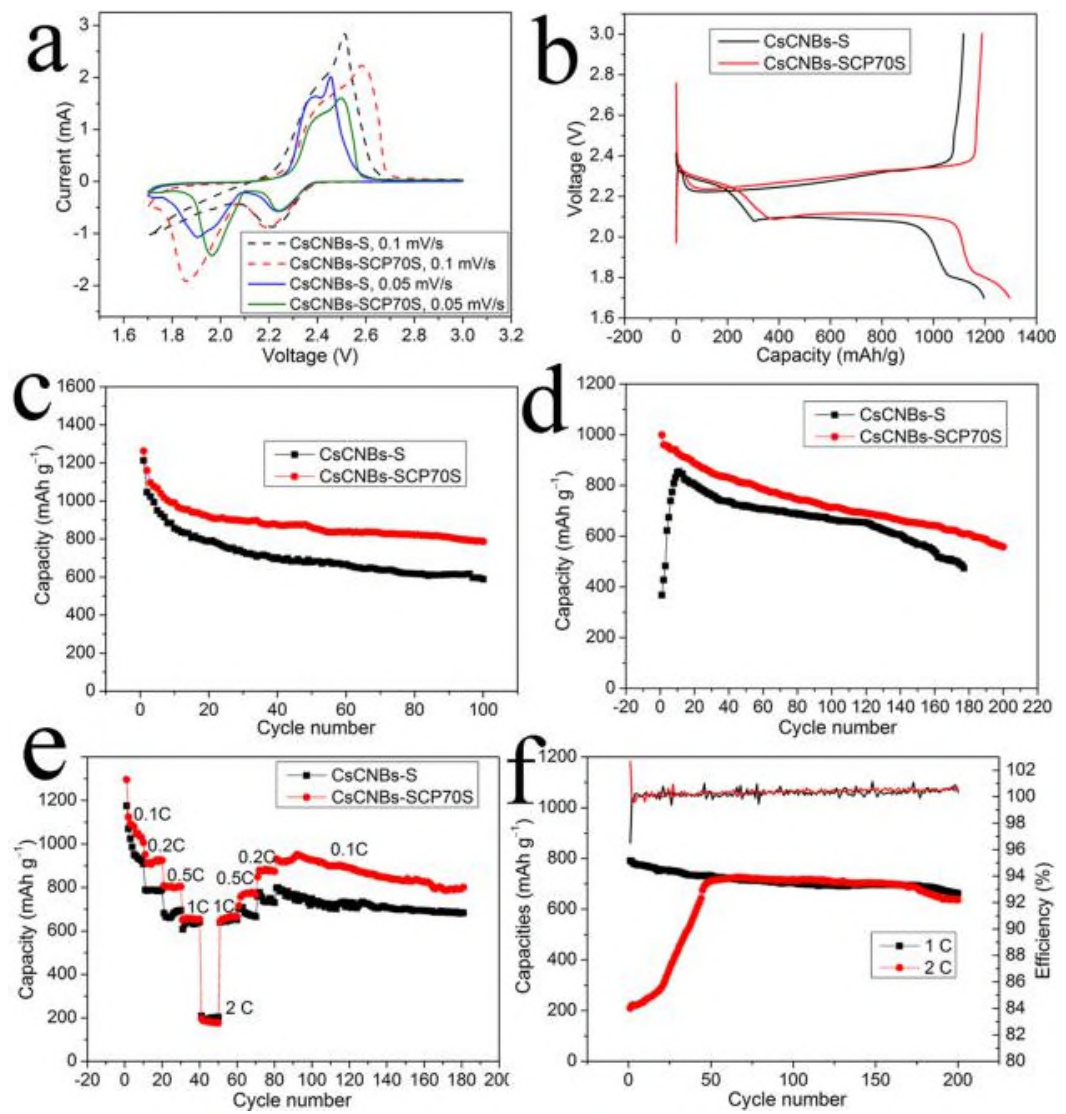

Figure 5. (a) $\mathrm{CV}$ curves at 0.05 and $0.1 \mathrm{mV} \mathrm{S}^{-1}$. (b) Initial discharge/charge curves at $0.1 \mathrm{C}$ for $\mathrm{CsCNBs}-\mathrm{S}$ and $\mathrm{CsCNBs}-\mathrm{SCP} 70 \mathrm{~S}$. Cyclic performances of $\mathrm{CsCNBs}^{-} \mathrm{S}$ and $\mathrm{CsCNBs}-\mathrm{SCP} 70 \mathrm{~S}$ at (c) 0.1 and (d) $0.5 \mathrm{C}$. (e) Rate performances of $\mathrm{CsCNBs}-\mathrm{S}$ and CsCNBs $-\mathrm{SCP} 70 \mathrm{~S}$. (f) Cyclic performances of $\mathrm{CsCNBs}-\mathrm{SCP} 70 \mathrm{~S}$ at 1 and $2 \mathrm{C}$.

currents under different sweep rates by using the RandlesSeveik equation, 29.59

$\mathrm{I}_{\mathrm{p}}=2.69 \times \quad 10 \mathrm{n} \mathrm{AD} \mathrm{V} \quad \mathrm{C}$
$51.5 \quad \mathrm{Li}^{0.50 .5} \mathrm{Li}$

where $I_{\mathrm{p}}(\mathrm{A})$ is the peak current, $n$ is equal to $2, A\left(\mathrm{~cm}^{2}\right)$ is the electrode area and is equal to $1.539 \mathrm{~cm}^{2}$ in this work, $\mathrm{v}\left(\mathrm{V} \mathrm{s}^{-1}\right)$ represents the sweep rate, and $C_{\mathrm{Li}}\left(\mathrm{mol} \mathrm{mL}^{-1}\right)$ means the lithiumion concentration of the electrolyte. As expected, $I_{\mathrm{p}}$ and $\mathrm{v}^{0.5}$ display a good linear relationship (Figure S2). Three $D$ Li were figured out from the the two cathodic peaks and one anodic peak. It is noteworthy that the actual reaction area is much larger than the electrode area; therefore, the resulting $D$ Li should be an apparent diffusion coefficient that is larger than the real one. Hereafter, $D_{1}, D_{2}$, and $D_{3}$ represent the $D_{\text {Li }}$ calculated from the two cathodic peaks $(1.7-2.0$ and $2.1-2.3 \mathrm{~V})$ and one anodic peak $(2.4-2.6 \mathrm{~V})$, respectively. The values of $D_{1}, D_{2}$, and $D_{3}$ of CsCNBs - SCP70S are $2.7 \times 10^{-8}, 9.3 \times 10^{-9}$, and $4.2 \times 10^{-8} \mathrm{~cm}^{2}$ $\mathrm{s}^{-1}$, respectively. The $D_{1}$ value of $\mathrm{CsCNBs}^{-\mathrm{S}}$ could not be figured out because the cathodic peak at low voltage becomes unrecognizable under a higher sweep rate. The $D_{2}$ and $D_{3}$ values of $\mathrm{CsCNBs}^{-} \mathrm{S}$ are $1.2 \times 10^{-8}$ and $4.0 \times 10^{-8} \mathrm{~cm}^{2} \mathrm{~s}^{-1}$, respectively, which are close to those of $\mathrm{CsCNBs}-\mathrm{SCP} 70 \mathrm{~S}$.

The EIS data are shown in Figure S3. Both the Nyquist plots of $\mathrm{CsCNBs}^{-} \mathrm{S}$ and $\mathrm{CsCNBs}-\mathrm{SCP} 70 \mathrm{~S}$ display a flattened semicircle and an oblique line. From the diameters of the semicircles, the charge-transfer resistances of $\mathrm{CsCNBs}^{-} \mathrm{S}$ and $\mathrm{CsCNBs}-\mathrm{SCP} 70 \mathrm{~S}$ are determined, which demonstrate that the charge-transfer resistance of $\mathrm{CsCNBs}-\mathrm{SCP} 70 \mathrm{~S}$ is only half of that of $\mathrm{CsCNBs}-\mathrm{S}$. This could be the result of the increased interfacial affinity between the polar TTCA-based SCP and polysulfides.

The initial discharge curves (Figure $5 \mathrm{~b}$ ) at $0.1 \mathrm{C}$ show three plateaus at $-2.3,2.1$, and $1.8 \mathrm{~V}$. Besides the two higher plateaus, the plateau at $-1.8 \mathrm{~V}$ resulted from the reduction of $\mathrm{LiNO}_{3}$ in the electrolyte. This is consistent with the reference which demonstrates that $\mathrm{LiNO}_{3}$ is irreversibly reduced when the voltage is below $1.9 \mathrm{~V} .{ }^{60}$ The plateau at $-1.8 \mathrm{~V}$ is shortened during the following five cycles. At $0.1 \mathrm{C}$, the cells made from $\mathrm{CsCNBs}^{-\mathrm{S}}$ and $\mathrm{CsCNBs}-\mathrm{SCP} 70 \mathrm{~S}$ exhibit initial capacities of 1197 and $1296 \mathrm{~mA} \mathrm{~h} \mathrm{~g}^{-1}$ (Figure 5b). After 100 cycles (Figure 5c), $\mathrm{CsCNBs}-\mathrm{S}$ and $\mathrm{CsCNBs}-\mathrm{SCP} 70 \mathrm{~S}$ achieve reversible capacities of 589 and $787 \mathrm{~mA} \mathrm{~h} \mathrm{~g}^{-1}$, respectively. When the current rate increases to $0.5 \mathrm{C}$ (Figure $5 \mathrm{~d}$ ), the initial capacities of $\mathrm{CsCNBs}^{-\mathrm{S}}$ and $\mathrm{CsCNBs}-\mathrm{SCP} 70 \mathrm{~S}$ decrease to 368 and 999 $\mathrm{mA} \mathrm{h} \mathrm{g}{ }^{-1}$, respectively. The low initial capacity of $\mathrm{CsCNBs}^{-} \mathrm{S}$ resulted from its low $D_{1}$ during the first few cycles. The capacity of $\mathrm{CsCNBs}^{-} \mathrm{S}$ shows a fast increase during the first 10 cycles, accompanied by an expansion of the plateau at $1.9 \mathrm{~V}$, as shown in Figure S4. This is because sulfur undergoes a dissolution-deposition process during the discharge/charge cycles. ${ }^{13,61}$ The sulfur redistributes in the $\mathrm{CsCNBs}$ to form a more accessible structure, which leads to an increase in the $D_{1}$ value and the capacity at the plateau at $1.9 \mathrm{~V}$. The better rate capability

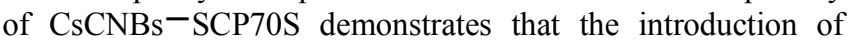
TTCA effectively improves the rate capability by enhancing the diffusion coefficient at $1.9 \mathrm{~V}$. The cell of $\mathrm{CsCNBs}^{-} \mathrm{S}$ shows 

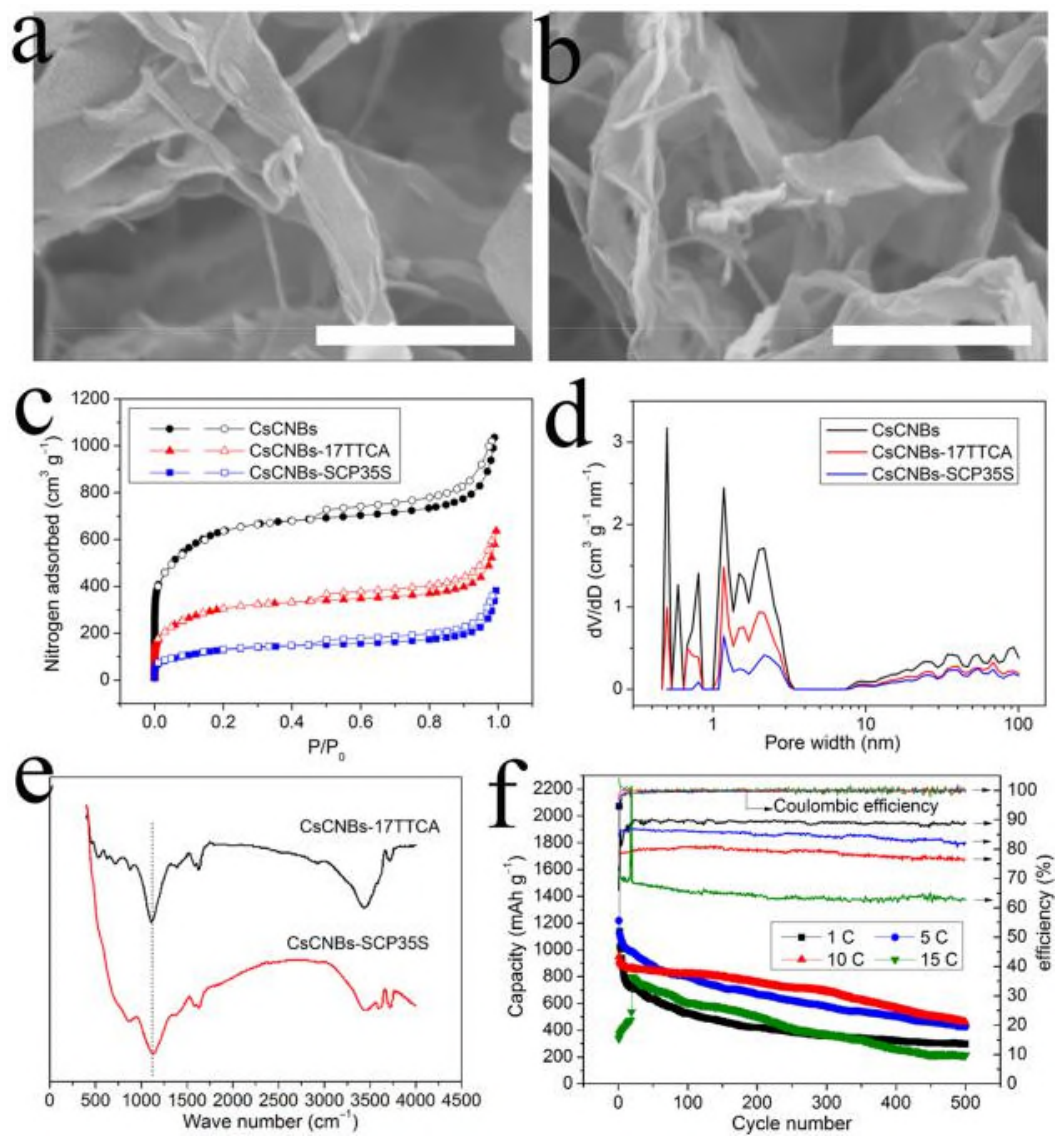

Figure 6. SEM images of (a) CsCNBs-17TTCA and (b) CsCNBs-SCP35S. The scale bars are $500 \mathrm{~nm}$. (c) Nitrogen adsorption/desorption isotherms and (d) PSD curves of CsCNBs, CsCNBs-17TTCA, and CsCNBs-SCP35S. (e) FTIR spectra of CsCNBs-17TTCA and CsCNBs- SCP35S. (f) Cyclic performances of $\mathrm{CsCNBs}-\mathrm{SCP} 35 \mathrm{~S}$ at $1,5,10$, and $15 \mathrm{C}$. The thin and thick solid lines denote the Coulombic and energy efficiencies, respectively.

an irregular charge curve with an abnormally high capacity at the 181 th cycle (Figure S5), which could have resulted from the severe shuttle effects. However, the cell of CsCNBs- SCP70S retains a capacity of $558 \mathrm{~mA} \mathrm{~h} \mathrm{~g} \mathrm{~g}^{-1}$ after 200 cycles. This indicates that TTCA effectively depresses the dissolution of LiPSs and improves the cycling stability.

To better show the rate capability, the cells of $\mathrm{CsCNBs}^{-} \mathrm{S}$ and $\mathrm{CsCNBs}-\mathrm{SCP} 70 \mathrm{~S}$ were charged/discharged at various current rates (Figure 5e). At $0.1 \mathrm{C}$, the capacities of the two composites decrease rapidly from -1300 to $-900 \mathrm{~mA} \mathrm{~h} \mathrm{~g}-1$. The capacities of $\mathrm{CsCNBs}^{-} \mathrm{S}$ at $0.2,0.5,1$, and $2 \mathrm{C}$ are around 790, 700, 640, and $210 \mathrm{~mA} \mathrm{~h} \mathrm{~g}$, respectively. When compared with $\mathrm{CsCNBs}-\mathrm{S}, \mathrm{CsCNBs}-\mathrm{SCP} 70 \mathrm{~S}$ shows higher capacities at the corresponding $\mathrm{C}$ rates, which are 930, 810, 660, and $200 \mathrm{~mA} \mathrm{~h}$ $\mathrm{g}^{-1}$, respectively. When the current rates switch back to $1,0.5$, 0.2 , and $0.1 \mathrm{C}$, the capacities can be largely recovered. After the rate cycles, the cells were further charged/discharged at $0.1 \mathrm{C}$ for 100 cycles. The final capacities of $\mathrm{CsCNBs}^{-} \mathrm{S}$ and CsCNBs - SCP70S are 683 and $800 \mathrm{~mA} \mathrm{~h}$, respectively. The high capacity and high rate capability of

$\mathrm{CsCNBs}-\mathrm{SCP} 70 \mathrm{~S}$ relative to $\mathrm{CsCNBs}^{-} \mathrm{S}$ probably resulted $\mathrm{g}^{-1}$ from two factors. First, the discharge products of SCP along with the pores of CsCNBs afford a strong interaction with LiPSs and depress the loss of LiPSs. Second, the discharge products of SCP may provide a lot of nucleation sites to prevent $\mathrm{Li}_{2} \mathrm{~S}_{2}, \mathrm{Li}_{2} \mathrm{~S}$, and $\mathrm{S}$ from growing into large grains which have less electrochemical activity. According to ref 62 , the trilithium salt of TTCA (TTCALi ${ }_{3}$ ) should be one of the final discharge products of SCP. Owing to the reversibility of the lithriation reaction of the polymeric disulfides of TTCA (Figure

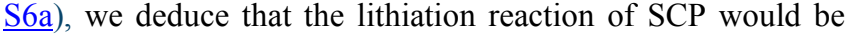
reversible or at least partially reversible (Figure S6b).

Even at $1 \mathrm{C}$ (Figure $5 \mathrm{f}$ ), the cell of $\mathrm{CsCNBs}-\mathrm{SCP} 70 \mathrm{~S}$ displays an initial capacity of $791 \mathrm{~mA} \mathrm{~h} \mathrm{~g}^{-1}$ and retains a reversible capacity of $662 \mathrm{~mA} \mathrm{~h} \mathrm{~g}^{-1}$ after 200 cycles. By further increasing the current rate to $2 \mathrm{C}$ (Figure $5 \mathrm{f}$ ), the cell of $\mathrm{CsCNBs}-\mathrm{SCP} 70 \mathrm{~S}$ needs 50 cycles to reach the maximum capacity $\left(726 \mathrm{~mA} \mathrm{~h} \mathrm{~g}^{-1}\right)$, which then decreases to $636 \mathrm{~mA} \mathrm{~h} \mathrm{g-1} \mathrm{at} \mathrm{the} \mathrm{200th} \mathrm{cycle.} \mathrm{The}$ increasing trend is attributed to the redistribution of sulfur that makes the structure of $\mathrm{CsCNBs}^{-}$SCP70S become more accessible. $^{13,61}$ The capacity of $\mathrm{CsCNBs}-\mathrm{SCP} 70 \mathrm{~S}$ at $2 \mathrm{C}$ is higher than that of HCSs/SCP and is comparable to those of graphene/SCP and carbon nanotubes/SCP.21,25,31

To further enhance the rate capability, a composite that partially retains the pore texture of $\mathrm{CsCNBs}$ was prepared by decreasing the TTCA and sulfur contents. The unoccupied pores would be favorable to the diffusion of lithium ions and therefore can gain a higher rate capability. According to the weight ratio of CsCNBs and TTCA, the content of TTCA in CsCNBs-17TTCA is $16.67 \%$, which agrees well with the value $(17.13 \%)$ calculated from the elemental analysis $(\mathrm{C}, 74.26 \%$; N, $4.38 \%$; H, $0.545 \%$; and $\mathrm{S}, 9.014 \%)$. After sulfur loading, the sulfur content is calculated to be $35.6 \%$ from the weight difference before and after vulcanization, which agrees with the results of the elemental analysis $(\mathrm{C}, 54.79 \%$; N, 2.87\%; H, 


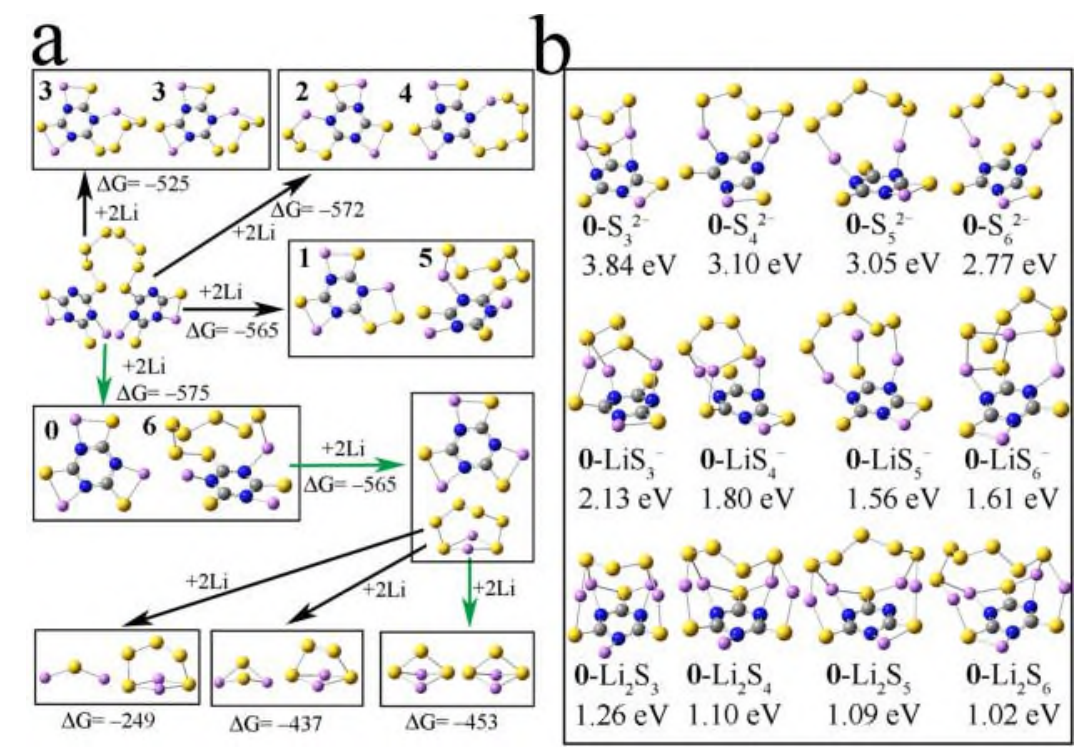

Figure 7. (a) Lithiation processes of SCP calculated from DFT theory. The unit of $\Delta \mathrm{G}$ is kJ mol${ }^{-1}$. The green arrows display the most likely pathway. (b) Optimized configurations and binding energies (eV) between the precipitation of 0 and possible LiPSs. The configurations of all models are the most stable ones. The $\mathrm{C}, \mathrm{N}, \mathrm{S}$, and $\mathrm{Li}$ atoms are denoted by gray, blue, yellow, and pink balls, respectively.

$0.149 \%$; and S, 37.794\%). Therefore, this composite is denoted as $\mathrm{CsCNB}-\mathrm{SCP} 35 \mathrm{~S}$. The SEM image of CsCNBs-17TTCA (Figure 6a) displays a rough surface with visible cracks. After loading with sulfur, the surface of $\mathrm{CsCNBs}-\mathrm{SCP} 35 \mathrm{~S}$ (Figure 6b) becomes smoother and the cracks become indistinct, indicating that the cracks are filled with SCPs.

The nitrogen adsorption-desorption isotherms of CsCNBs, CsCNBs-17TTCA, and CsCNBs-SCP35S are shown in Figure 6c. All these isotherms exhibit large adsorption at low pressure and hysteresis loops at high pressure, which represent the existence of micropores and mesopores. The BrunauerEmmett-Teller surface areas of CsCNBs, CsCNBs-17TTCA, and $\mathrm{CsCNBs}-\mathrm{SCP} 35 \mathrm{~S}$ are 2212, 1087, and $477 \mathrm{~m}^{2} \mathrm{~g}^{-1}$, respectively. The pore volumes of $\mathrm{CsCNBs}$, $\mathrm{CsCNBs}^{-}$ 17TTCA, and CsCNBs-SCP35S are 1.53, 0.90, and $0.52 \mathrm{~cm}^{3}$ $\mathrm{g}^{-1}$, respectively. The pore size distribution (PSD) curves of CsCNBs, CsCNBs-17TTCA, and $\mathrm{CsCNBs-SCP35S}$ are obtained from the density functional theory (DFT) and are shown in Figure 6d. In the range of less than $1 \mathrm{~nm}$, the heights of the PSD curves of CsCNBs-17TTCA and CsCNBsSCP35S are significantly lower than those of CsCNBs, revealing that the pores less than $1 \mathrm{~nm}$ are preferentially filled with TTCA and SCPs. In the range of more than $1 \mathrm{~nm}$, all the PSD curves display similar profiles with different heights, owing to the uniform filling of TTCA and SCPs within the pores.

The FTIR spectra of CsCNBs-17TTCA and CsCNBsSCP35S (Figure 6e) reveal that the vibration of $\mathrm{C}=\mathrm{S}$ at 1120 $\mathrm{cm}^{-1}$ is obviously weakened after vulcanization, ${ }^{31}$ which indicates the formation of SCP. The Raman spectra of CsCNBs-17TTCA and CsCNBs-SCP35S (Figure S7) show two peaks at 1340 and $1591 \mathrm{~cm}^{-1}$, which are the same as those of CsCNBs. A comparison of the TG curves of CsCNBs- 17TTCA and $\mathrm{CsCNBs}-\mathrm{SCP} 35 \mathrm{~S}$ (Figure S8) reveals different pyrolysis processes, implying the formation of SCP.

The electrochemical performances of $\mathrm{CsCNBs}-\mathrm{SCP} 35 \mathrm{~S}$ are shown in Figure 6f. The initial discharge/charge capacities at 1, 5, and $10 \mathrm{C}$ are 2073/1442, 1218/1139, and 949/922 $\mathrm{mA} \mathrm{h}$, respectively. The initial discharge capacity at $1 \mathrm{C}$ is larger than the theoretical capacity of sulfur, which resulted from the reduction of $\mathrm{LiNO}_{3}$ catalyzed by the naked surface of CNBs. ${ }^{13,60}$ Correspondingly, the initial discharge curve at $1 \mathrm{C}$ presents a long plateau at $1.7 \mathrm{~V} .^{13}$ This plateau is shortened in the initial discharge curve at $5 \mathrm{C}$ and disappears at $10 \mathrm{C}$. When the cell is charged/discharged at $15 \mathrm{C}$, the voltage window is expanded to 1.5-3.0 $\mathrm{V}$ to make sure the presence of the low-voltage plateau. The initial discharge/charge capacities at $15 \mathrm{C}$ are $339 / 354 \mathrm{~mA} \mathrm{~h}$ $\mathrm{g}^{-1}$. After activation for 20 cycles, the discharge/charge capacities at $15 \mathrm{C}$ reach the maximum values $\left(796 / 785 \mathrm{~mA} \mathrm{~h} \mathrm{~g}^{-1}\right)$. After 100 cycles, the capacities at 1, 5, 10, and $15 \mathrm{C}$ are 525, 799, 821 , and $610 \mathrm{~mA} \mathrm{~h} \mathrm{~g}^{-1}$, respectively. Relative to the capacities of the second cycle, the capacity retentions at $1,5,10$, and $15 \mathrm{C}$ are calculated to be $46,71,89$, and $77 \%$ (the capacity retention at 15 $\mathrm{C}$ is relative to the highest capacity of $796 \mathrm{~mA} \mathrm{~h} \mathrm{~g}^{-1}$, as the same below), respectively. Even after 500 cycles, reversible capacities of around 298, 426, 459, and $215 \mathrm{~mA} \mathrm{~h} \mathrm{~g}^{-1}$ are still attained for the cells at $1,5,10$, and $15 \mathrm{C}$, respectively, corresponding to the capacity retentions of $26,38,50$, and $27 \%$. Because the loss of LiPSs decreases with the current rates, ${ }^{13}$ the capacity retention increases as the current rate increases from 1 to $10 \mathrm{C}$. This indicates that the capacity decay at 1,5 , and $10 \mathrm{C}$ probably resulted from the slow loss of LiPSs. However, the capacity retention at $15 \mathrm{C}$ is even lower than that at $1 \mathrm{C}$. The capacity decay at $15 \mathrm{C}$ is different from those at lower rates, and is probably induced by the accumulation of $\mathrm{Li}_{2} \mathrm{~S}$ outside the CNBs. When compared with $\mathrm{CsCNBs}-\mathrm{SCP} 70 \mathrm{~S}$, CsCNBs-SCP35S displays much better rate capability because the unoccupied pores facilitate the fast transportation of lithium ions. The rate capability of CsCNBs-SCP35S is even higher than that of SCP microtubes because of the high electron conductivity of the CNBs. As shown in Figure 6f, the average Coulombic efficiencies (CEs) at 1, 5, 10, and $15 \mathrm{C}$ are close to $100 \%$ during the first 500 cycles. The energy efficiencies are figured out from the integrations of the charge and discharge curves. ${ }^{63}$ The average energy efficiencies achieved at $1,5,10$, and $15 \mathrm{C}$ are $89,85,79$, and $64 \%$, 


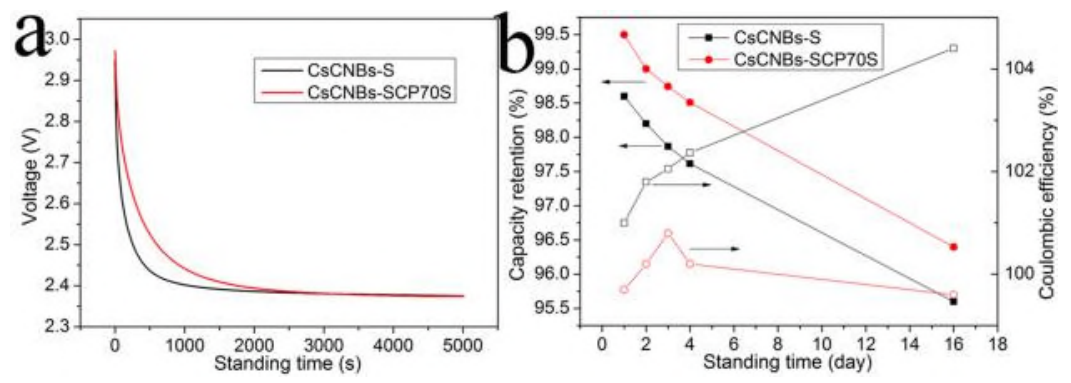

Figure 8. (a) Voltage decay curves of $\mathrm{CsCNBs}-\mathrm{S}$ and $\mathrm{CsCNBs}-\mathrm{SCP} 70 \mathrm{~S}$. (b) Capacity retentions and $\mathrm{CEs}$ of $\mathrm{CsCNBs}-\mathrm{S}$ and $\mathrm{CsCNBs}-\mathrm{SCP} 70 \mathrm{~S}$ after standing for $1-16$ days.

respectively. Just as expected, the energy efficiencies decrease as the currents increase.

To better understand the lithiation process of SCP, DFT calculations are performed for all possible intermediates by using Gaussian 09. ${ }^{64}$ The intermediates are denoted as $0-6$ according to the number of additional sulfur atoms bonded to $\mathrm{TTCALi}_{3}$. As shown in Figure 7a, the most likely pathway is denoted by the green arrows. There are four possible reactions during the first lithiation step. The Gibbs free-energy changes $(A G)$ of the reactions to $(0,6),(1,5),(2,4)$, and $(3,3)$ are -575 , $-565,-572$, and $-525 \mathrm{~kJ} \mathrm{~mol}^{-1}$, respectively. Obviously, the reaction to $(0,6)$ is the most favorable pathway in energy, and the reaction to $(3,3)$ is the most unlikely pathway, which is different from Li2s8 (Figure S9) and the covalently stabilized sulfur where the lithiation preferentially happens at the middle of the polysulfide chain. ${ }^{27}$ It is noted that $A G$ values of the reactions to $(0,6),(1,5)$, and $(2,4)$ are very close to each other, and therefore all the three reactions probably happen during lithiation, especially at high rate currents. During the second lithiation step, $A G$ values of the reactions to $\left(0, \mathrm{Li}_{2} \mathrm{~S} 6\right),\left(1, \mathrm{Li}_{2} \mathrm{~S} 5\right)$, $\left(2, \mathrm{Li}_{2} \mathrm{~S}_{4}\right),\left(3, \mathrm{Li}_{2} \mathrm{~S}_{3}\right),\left(4, \mathrm{Li}_{2} \mathrm{~S}_{2}\right)$, and $\left(5, \mathrm{Li}_{2} \mathrm{~S}\right)$ are $-565,-560$, $-549,-484,-490$, and $-244 \mathrm{~kJ} \mathrm{~mol}^{-1}$, respectively. The reaction to $\left(0, \mathrm{Li}_{2} \mathrm{~S} 6\right)$ is the most likely pathway, and only this reaction is shown in Figure 7a. The first two lithiation steps of SCP release $-1140 \mathrm{~kJ} \mathrm{~mol}^{-1}$ of energy, which is close to the AG value $\left(-1121 \mathrm{~kJ} \mathrm{~mol}^{-1}\right)$ of the first two lithiation steps of $\mathrm{S}_{8}$ (Figure S9). Therefore, the first two lithiation steps of SCP correspond to the higher plateau at $2.3 \mathrm{~V}$ and the following lithiation steps correspond to the lower plateau at $2.1 \mathrm{~V}$, which lead to the similarity of the discharge curves between SCP and sulfur (Figure 5b). During the third lithiation step, the reaction of $\mathrm{Li}_{2} \mathrm{~S}_{6}$ to $\left(\mathrm{Li}_{2} \mathrm{~S}_{3}, \mathrm{Li}_{2} \mathrm{~S}_{3}\right)$ is the most likely pathway with a $A G$ value of $-453 \mathrm{~kJ} \mathrm{~mol}^{-1}$, followed by the reaction to $\left(\mathrm{Li}_{2} \mathrm{~S}_{2}, \mathrm{Li}_{2} \mathrm{~S}_{4}\right)$ with a $A G$ value of $-437 \mathrm{~kJ} \mathrm{~mol}^{-1}$. The reaction to $\left(\mathrm{Li}_{2} \mathrm{~S}, \mathrm{Li}_{2} \mathrm{~S} 5\right)$ is the most unlikely pathway because of the relatively high energy of the gas-phase $\mathrm{Li}_{2} \mathrm{~S}$. Finally, $\mathrm{Li}_{2} \mathrm{~S}_{3}$ would react with lithium to form insoluble ${ }_{\mathrm{Li} 2 \mathrm{~S} 2}$ and $\mathrm{Li}_{2} \mathrm{~S}$.

According to the above DFT results, soluble LiPSs would form in the lithiation process. Therefore, the dissolution of LiPSs could not be completely eliminated by the introduction of SCP. However, the diffusion coefficient of the intermediates $0-6$ is definitely lower than that of the long-chain LiPSs because of the larger mass and volume of $0-6$, which depress the loss of active materials and therefore lead to better cycle stability (Figure $5 \mathrm{c}, \mathrm{d}$ ). Moreover, the discharge product 0 is insoluble in the electrolyte and will be precipitated before the formation of LiPSs (Figure 7a). The precipitation of 0 provides numerous surface sites for adsorbing LiPSs. The optimized configurations and the binding energies between the precipitation of 0 and possible LiPSs are figured out in Figure 7b. Obviously, the binding energies decrease with a decrease in the ionic charge numbers and an increase in the number of sulfur atoms in LiPSs. Even the lowest binding energy (1.02 eV of $0-\mathrm{Li}_{2} \mathrm{~S}_{6}$ ) is higher than the binding energy (less than $1 \mathrm{eV}$ ) between LiPSs and the nonpolar carbon surface. ${ }^{65}$ The high binding energy between LiPSs and 0 could prevent the growth of ${ }_{\mathrm{Li} 2 \mathrm{~S} 2}$ and $\mathrm{Li}_{2} \mathrm{~S}$ into large grains by providing numerous nucleation sites, which enhances the cyclic stability and the high rate capability of $\mathrm{CsCNBs}-\mathrm{SCP} 70 \mathrm{~S}$.

The low diffusion coefficient of the intermediates 0-6 and the high binding energy between 0 and LiPSs also decrease the self-discharge rate. As shown in Figure 8a, the voltage of CsCNBs-SCP70S decreases more slowly than that of $\mathrm{CsCNBs}-\mathrm{S}$. The capacity retentions (Figure 8b) of CsCNBs-SCP70S after standing for 1-16 days are also higher than those of $\mathrm{CsCNBs}-\mathrm{S}$. The $\mathrm{CEs}$ (charging/ discharging capacity $\times 100 \%$ ) of the first cycle after standing demonstrate that the $\mathrm{CEs}$ of $\mathrm{CsCNBs}-\mathrm{S}$ increase with the standing time, whereas the CEs of CsCNBs-SCP70S are close to $100 \%$ for all these standing times.

\section{CONCLUSION}

In summary, we present a new strategy to prepare SCP composites with desired morphologies for $\mathrm{Li}-\mathrm{S}$ batteries. With this strategy, the tailoring of the morphologies of SCP is simplified to the tailoring of the morphologies of carbon materials. As a proof of concept, hierarchical CsCNBs were chosen as the templates for the SCP composites. The hierarchical structure of CsCNBs was successfully retained after loading with SCP. Owing to the advantage of SCP to sulfur, the composite of $\mathrm{CsCNBs-SCP}$ showed higher capacity, higher rate capability, and lower self-discharge rate as compared with $\mathrm{CsCNBs}-\mathrm{S}$. The lithiation process of SCP was further studied by the DFT calculations which explain the presence of the discharging plateau at $2.3 \mathrm{~V}$ of the SCP composites and the lower self-discharge rate. To further enhance the rate capability, a composite with unfilled pores was prepared by decreasing the TTCA and sulfur contents. This composite showed a rate capability up to $15 \mathrm{C}$ with a maximum capacity of $796 \mathrm{~mA} \mathrm{~h} \mathrm{~g}$. The initial charge capacities at 1,5 , and $10 \mathrm{C}$ were 1442,1139 , and $922 \mathrm{~mA} \mathrm{~h}$, respectively.

\section{$\mathrm{g}^{-1}$ ASSOCIATED CONTENT \\ * s Supporting Information}

The Supporting Information is available free of charge on the ACS Publications website at DOI: 10.1021/acsami.8b03611. 
$\mathrm{CV}$ curves, linear relationship between sweep rates and peak currents, discharge curves of $\mathrm{CsCNBs}-\mathrm{S}$ at $0.5 \mathrm{C}$, lithiation/delithiation processes, Raman spectra, TG curves, and the theoretical lithiation processes of sulfur $(\underline{\mathrm{PDF}})$

\section{- AUTHOR INFORMATION \\ Corresponding Author \\ *E-mail: zoujizhao@szu.edu.cn. \\ ORAD}

Shao-Zhong Zeng: 0000-0002-9548-5287

Haitao Huang: 0000-0002-3861-2702

Notes

The authors declare no competing financial interest.

\section{ACKNOWLEDGMENTS}

We would like to thank the National Natural Science Foundation of China (nos. 51202150, 51272161 and 21703141), Basic Research Program of Shenzhen (JCYJ20150324141711663 and JCYJ20170818101932570), Program of Introducing Innovative Research Team in Dongguan (no. 2014607109), foundation of the State Key Laboratory $o \mathrm{f}$ Solidification Processing $\mathrm{i} n$ NWPU(SKLSP201110), and the Hong Kong Polytechnic University (Project no. 1-ZVGH).

\section{REFERENCES}

(1) Liu, X.; Huang, J.-Q.; Zhang, Q.; Mai, L. Nanostructured Metal Oxides and Sulfides for Lithium-Sulfur Batteries. Adv. Mater. 2017, 29, 1601759.

(2) Manthiram, A.; Chung, S.-H.; Zu, C. Lithium-Sulfur Batteries: Progress and Prospects. Adv. Mater. 2015, 27, 1980-2006.

(3) Chen, S.; Huang, X.; Liu, H.; Sun, B.; Yeoh, W.; Li, K.; Zhang, J.; Wang, G. 3D Hyperbranched Hollow Carbon Nanorod Architectures for High-Performance Lithium-Sulfur Batteries. Adv. Energy Mater. 2014, 4, 1301761.

(4) Moon, S.; Jung, Y. H.; Jung, W. K.; Jung, D. S.; Choi, J. W.; Kim, D. K. Encapsulated Monoclinic Sulfur for Stable Cycling of Li-S Rechargeable Batteries. Adv. Mater. 2013, 25, 6547-6553.

(5) Li, Z.; Huang, Y.; Yuan, L.; Hao, Z.; Huang, Y. Status and prospects in sulfur-carbon composites as cathode materials for rechargeable lithium-sulfur batteries. Carbon 2015, 92, 41-63.

(6) Zhang, B.; Qin, X.; Li, G. R.; Gao, X. P. Enhancement of long stability of sulfur cathode by encapsulating sulfur into micropores of carbon spheres. Energy Environ. Sci. 2010, 3, 1531-1537.

(7) Jin, F.; Xiao, S.; Lu, L.; Wang, Y. Efficient Activation of HighLoading Sulfur by Small CNTs Confined Inside a Large CNT for High-Capacity and High-Rate Lithium-Sulfur Batteries. Nano Lett. 2016, 16, 440-447.

(8) Zhao, M.-Q.; Zhang, Q.; Huang, J.-Q.; Tian, G.-L.; Nie, J.-Q.; Peng, H.-J.; Wei, F. Unstacked double-layer templated graphene for high-rate lithium-sulphur batteries. Nat. Commun. 2014, 5, 3410.

(9) Pang, Q.; Kundu, D.; Cuisinier, M.; Nazar, L. F. Surfaceenhanced redox chemistry of polysulphides on a metallic and polar host for lithium-sulphur batteries. Nat. Commun. 2014, 5, 4759. (10)Ji, X.; Lee, K. T.; Nazar, L. F. A highly ordered nanostructured carbon-sulphur cathode for lithium-sulphur batteries. Nat. Mater. 2009, 8, 500-506.

(0) Sun, Q.; He, B.; Zhang, X.-Q.; Lu, A.-H. Engineering of Hollow Core-Shell Interlinked Carbon Spheres for Highly Stable Lithium-Sulfur Batteries. ACS Nano 2015, 9, 8504-8513.

(1) Chen, S.; Huang, X.; Sun, B.; Zhang, J.; Liu, H.; Wang, G. Multishelled hollow carbon nanospheres for lithium-sulfur batteries with superior performances. J. Mater. Chem. A 2014, 2, 16199-16207.
(0) Zeng, S.-Z.; Zeng, X.; Tu, W.; Yao, Y.; Yu, L.; Wu, H.; Jin, W.; Huang, H.; Zou, J. Facile and tailored synthesis of ultrahigh-surfacearea clews of carbon nanobelts for high-rate lithium-sulfur batteries. $J$. Mater. Chem. A 2017, 5, 23209-23220.

(1) Hu, C.; Kirk, C.; Cai, Q.; Cuadrado-Collados, C.; SilvestreAlbero, J.; Rodríguez-Reinoso, F.; Biggs, M. J. A High-VolumetricCapacity Cathode Based on Interconnected Close-Packed N-Doped Porous Carbon Nanospheres for Long-Life Lithium-Sulfur Batteries. Adv. Energy Mater. 2017, 7, 1701082.

(2) Lyu, Z.; Xu, D.; Yang, L.; Che, R.; Feng, R.; Zhao, J.; Li, Y.; Wu, Q.; Wang, X.; Hu, Z. Hierarchical carbon nanocages confining high-loading sulfur for high-rate lithium-sulfur batteries. Nano Energy $2015,12,657-665$.

(3) Singhal, R.; Chung, S.-H.; Manthiram, A.; Kalra, V. A freestanding carbon nanofiber interlayer for high-performance lithiumsulfur batteries. J. Mater. Chem. A 2015, 3, 4530-4538.

(4) Zeng, S.-Z.; Yao, Y.; Huang, L.; Wu, H.; Peng, B.; Zhang, Q.; Li, X.; Yu, L.; Liu, S.; Tu, W.; Lan, T.; Zeng, X.; Zou, J. Facile Synthesis of Ultrahigh-Surface-Area Hollow Carbon Nanospheres and their Application in Lithium-Sulfur Batteries. Chem.-Eur. J. 2018, 24, 1988-1997.

(5) Liang, X.; Wen, Z.; Liu, Y.; Zhang, H.; Huang, L.; Jin, J. Highly dispersed sulfur in ordered mesoporous carbon sphere as a composite cathode for rechargeable polymer Li/S battery. J. Power Sources 2011, 196, 3655-3658.

(6) Du, X.-L.; You, Y.; Yan, Y.; Zhang, D.; Cong, H.-P.; Qin, H.; Zhang, C.; Cao, F.-F.; Jiang, K.-C.; Wang, Y.; Xin, S.; He, J.-B. Conductive Carbon Network inside a Sulfur-Impregnated Carbon Sponge: A Bioinspired High-Performance Cathode for Li-S Battery. ACS Appl. Mater. Interfaces 2016, 8, 22261-22269.

(7) Simmonds, A. G.; Griebel, J. J.; Park, J.; Kim, K. R.; Chung, W. J.; Oleshko, V. P.; Kim, J.; Kim, E. T.; Glass, R. S.; Soles, C. L.; Sung, Y.-E.; Char, K.; Pyun, J. Inverse Vulcanization of Elemental Sulfur to Prepare Polymeric Electrode Materials for Li-S Batteries. ACS Macro Lett. 2014, 3, 229-232.

(8) Hu, G.; Sun, Z.; Shi, C.; Fang, R.; Chen, J.; Hou, P.; Liu, C.; Cheng, H.-M.; Li, F. A Sulfur-Rich Copolymer@CNT Hybrid Cathode with Dual-Confinement of Polysulfides for High-Performance Lithium-Sulfur Batteries. Adv. Mater. 2017, 29, 1603835.

(9) Wang, J.; Yang, J.; Xie, J.; Xu, N. A novel conductive polymersulfur composite cathode material for rechargeable lithium batteries. Adv. Mater. 2002, 14, 963-965.

(10) Xiao, L.; Cao, Y.; Xiao, J.; Schwenzer, B.; Engelhard, M. H.; Saraf, L. V.; Nie, Z.; Exarhos, G. J.; Liu, J. A Soft Approach to Encapsulate Sulfur: Polyaniline Nanotubes for Lithium-Sulfur Batteries with Long Cycle Life. Adv. Mater. 2012, 24, 1176-1181.

(11) Talapaneni, S. N.; Hwang, T. H.; Je, S. H.; Buyukcakir, O.; Choi, J. W.; Coskun, A. Elemental-Sulfur-Mediated Facile Synthesis of a Covalent Triazine Framework for High-Performance Lithium-Sulfur Batteries. Angew. Chem., Int. Ed. 2016, 55, 3106-3111.

(12) Li, B.; Li, S.; Xu, J.; Yang, S. A new configured lithiated siliconsulfur battery built on 3D graphene with superior electrochemical performances. Energy Environ. Sci. 2016, 9, 2025-2030.

(13) Duan, B.; Wang, W.; Wang, A.; Yuan, K.; Yu, Z.; Zhao, H.; Qiu, J.; Yang, Y. Carbyne polysulfide as a novel cathode material for lithium/sulfur batteries. J. Mater. Chem. A 2013, 1, 13261-13267.

(14) Xu, N.; Qian, T.; Liu, X.; Liu, J.; Chen, Y.; Yan, C. Greatly Suppressed Shuttle Effect for Improved Lithium Sulfur Battery Performance through Short Chain Intermediates. Nano Lett. 2017, 17, 538-543.

(15) Chung, W. J.; Griebel, J. J.; Kim, E. T.; Yoon, H.; Simmonds, A. G.; Ji, H. J.; Dirlam, P. T.; Glass, R. S.; Wie, J. J.; Nguyen, N. A.; Guralnick, B. W.; Park, J.; Somogyi, A.; Theato, P.; Mackay, M. E.; Sung, Y.-E.; Char, K.; Pyun, J. The use of elemental sulfur as an alternative feedstock for polymeric materials. Nat. Chem. 2013, 5, 518-524.

(16) Kim, H.; Lee, J.; Ahn, H.; Kim, O.; Park, M. J. Synthesis of three-dimensionally interconnected sulfur-rich polymers for cathode 
materials of high-rate lithium-sulfur batteries. Nat. Commun. 2015, 6,7278 .

(30) Yu, B.-C.; Jung, J.-W.; Park, K.; Goodenough, J. B. A new approach for recycling waste rubber products in Li-S batteries. Energy Environ. Sci. 2017, 10, 86-90.

(31) Zeng, S.-Z.; Yao, Y.; Zeng, X.; He, Q.; Zheng, X.; Chen, S.; $\mathrm{Tu}, \mathrm{W}$.; Zou, J. A composite of hollow carbon nanospheres and sulfurrich polymers for lithium-sulfur batteries. J. Power Sources 2017, 357, $11-18$.

(32) Yin, L.; Wang, J.; Lin, F.; Yang, J.; Nuli, Y. Polyacrylonitrile/ graphene composite as a precursor to a sulfur-based cathode material for high-rate rechargeable Li-S batteries. Energy Environ. Sci. 2012, 5, 6966-6972.

(33) Xu, F.; Yang, S.; Jiang, G.; Ye, Q.; Wei, B.; Wang, H. Fluorinated, Sulfur-Rich, Covalent Triazine Frameworks for Enhanced Confinement of Polysulfides in Lithium-Sulfur Batteries. ACS Appl. Mater. Interfaces 2017, 9, 37731-37738.

(34) Su, Y.-S.; Manthiram, A. Lithium-sulphur batteries with a microporous carbon paper as a bifunctional interlayer. Nat. Commun. 2012, 3, 1166.

(35) Qie, L.; Zu, C.; Manthiram, A. A High Energy LithiumSulfur Battery with Ultrahigh-Loading Lithium Polysulfide Cathode and its Failure Mechanism. Adv. Energy Mater. 2016, 6, 1502459.

(36) Chung, S.-H.; Han, P.; Singhal, R.; Kalra, V.; Manthiram, A. Electrochemically Stable Rechargeable Lithium-Sulfur Batteries with a Microporous Carbon Nanofiber Filter for Polysulfide. $A d v$ Energy Mater. 2015, 5, 1500738.

(37) Lim, S.; Lilly Thankamony, R.; Yim, T.; Chu, H.; Kim, Y.J.; Mun, J.; Kim, T.-H. Surface Modification of Sulfur Electrodes by Chemically Anchored Cross-Linked Polymer Coating for LithiumSulfur Batteries. ACS Appl. Mater. Interfaces 2015, 7, 1401-1405.

(38) Yang, Y.; Yu, G.; Cha, J. J.; Wu, H.; Vosgueritchian, M.; Yao, Y.; Bao, Z.; Cui, Y. Improving the Performance of LithiumSulfur Batteries by Conductive Polymer Coating. ACS Nano 2011, $5,9187-9193$

(39) Liu, M.; Jiang, H. R.; Ren, Y. X.; Zhou, D.; Kang, F. Y.; Zhao, T. S. In-situ Fabrication of a Freestanding Acrylate-based Hierarchical Electrolyte for Lithium-sulfur Batteries. Electrochim. Acta 2016, 213, 871-878.

(40) Chen, W.; Qian, T.; Xiong, J.; Xu, N.; Liu, X.; Liu, J.; Zhou, J.; Shen, X.; Yang, T.; Chen, Y.; Yan, C. A New Type of Multifunctional Polar Binder: Toward Practical Application of High Energy Lithium Sulfur Batteries. Adv. Mater. 2017, 29, 1605160.

(41) Milroy, C.; Manthiram, A. An Elastic, Conductive, Electroactive Nanocomposite Binder for Flexible Sulfur Cathodes in Lithium-Sulfur Batteries. Adv. Mater. 2016, 28, 9744-9751.

(42) Tao, X.; Liu, Y.; Liu, W.; Zhou, G.; Zhao, J.; Lin, D.; Zu, C.; Sheng, O.; Zhang, W.; Lee, H.-W.; Cui, Y. Solid-State Lithium-Sulfur Batteries Operated at $37{ }^{\circ} \mathrm{C}$ with Composites of Nanostructured Li7La3Zr2O12/Carbon Foam and Polymer. Nano Lett. 2017, 17, 2967-2972.

(43) Liu, M.; Zhou, D.; He, Y.-B.; Fu, Y.; Qin, X.; Miao, C.; Du, H.; Li, B.; Yang, Q.-H.; Lin, Z.; Zhao, T. S.; Kang, F. Novel gel polymer electrolyte for high-performance lithium-sulfur batteries. Nano Energy 2016, 22, 278-289.

(44) Ai, G.; Dai, Y.; Ye, Y.; Mao, W.; Wang, Z.; Zhao, H.; Chen, Y.; Zhu, J.; Fu, Y.; Battaglia, V.; Guo, J.; Srinivasan, V.; Liu, G. Investigation of surface effects through the application of the functional binders in lithium sulfur batteries. Nano Energy 2015, 16, 28-37.

(45) Zeng, F.; Wang, W.; Wang, A.; Yuan, K.; Jin, Z.; Yang, Y.s. Multidimensional Polycation $\beta$-Cyclodextrin Polymer as an Effective Aqueous Binder for High Sulfur Loading Cathode in Lithium-Sulfur Batteries. ACS Appl. Mater. Interfaces 2015, 7, 26257-26265.

(46) Eftekhari, A.; Kim, D.-W. Cathode materials for lithiumsulfur batteries: a practical perspective. J. Mater. Chem. A 2017, 5, 17734- 17776 .

(47) Yang, C.-P.; Yin, Y.-X.; Ye, H.; Jiang, K.-C.; Zhang, J.; Guo, Y.-G. Insight into the Effect of Boron Doping on Sulfur/Carbon
Cathode in Lithium-Sulfur Batteries. ACS Appl. Mater. Interfaces 2014, 6, 8789-8795.

(48) Gao, W.; Feng, X.; Zhang, T.; Huang, H.; Li, J.; Song, W. OneStep Pyrolytic Synthesis of Nitrogen and Sulfur Dual-Doped Porous Carbon with High Catalytic Activity and Good Accessibility to Small Biomolecules. ACS Appl. Mater. Interfaces 2014, 6, 19109-19117.

(49) Pang, Q.; Tang, J.; Huang, H.; Liang, X.; Hart, C.; Tam, K. C.; Nazar, L. F. A Nitrogen and Sulfur Dual-Doped Carbon Derived from Polyrhodanine@Cellulose for Advanced Lithium-Sulfur Batteries. $A d v$. Mater. 2015, 27, 6021-6028.

(50) Pei, F.; An, T.; Zang, J.; Zhao, X.; Fang, X.; Zheng, M.; Dong, Q.; Zheng, N. From Hollow Carbon Spheres to N-Doped Hollow Porous Carbon Bowls: Rational Design of Hollow Carbon Host for Li-S Batteries. Adv. Energy Mater. 2016, 6, 1502539.

(51) Zhou, W.; Wang, C.; Zhang, Q.; Abruna, H. D.; He, Y.; Wang, J.; Mao, S. X.; Xiao, X. Tailoring Pore Size of Nitrogen-Doped Hollow Carbon Nanospheres for Confining Sulfur in Lithium-Sulfur Batteries. Adv. Energy Mater. 2015, 5, 1401752.

(52) Zu, C.; Manthiram, A. Hydroxylated Graphene-Sulfur Nanocomposites for High-Rate Lithium-Sulfur Batteries. Adv. Energy Mater. 2013, 3, 1008-1012.

(53) Chen, H.; Wang, C.; Dong, W.; Lu, W.; Du, Z.; Chen, L. Monodispersed Sulfur Nanoparticles for Lithium-Sulfur Batteries with Theoretical Performance. Nano Lett. 2015, 15, 798-802.

(54) Almeida, C.; Costa, H.; Kadhirvel, P.; Queiroz, A. M.; Dias, R. C. S.; Costa, M. R. P. F. N. Electrochemical activity of sulfur networks synthesized through RAFT polymerization. J. Appl. Polym. Sci. 2016, $133,43993$.

(55) Wang, J.; He, Y.-S.; Yang, J. Sulfur-Based Composite Cathode Materials for High-Energy Rechargeable Lithium Batteries. Adv. Mater. 2015, 27, 569-575.

(56) Zeng, S.-Z.; Jin, N.-Z.; Zhang, H.-L.; Hai, B.; Chen, X.-H.; Shi, J. High-modulus all-carbon ladder polymer of hydroquinone and formaldehyde that bridges the gap between single-strand polymers and graphene nanoribbons. RSC Adv. 2014, 4, 18676-18682.

(57) Assary, R. S.; Curtiss, L. A.; Moore, J. S. Toward a Molecular Understanding of Energetics in Li-S Batteries Using Nonaqueous Electrolytes: A High-Level Quantum Chemical Study. J. Phys. Chem. C 2014, 118, 11545-11558.

(58) Kucharski, M.; Chmiel-Szukiewicz, E. Reactions of trithiocyanuric acid with oxiranes. I. Synthesis of polyetherols. J. Appl. Polym. Sci. 2000, 76, 439-445.

(59) Huang, J.-Q.; Zhuang, T.-Z.; Zhang, Q.; Peng, H.-J.; Chen, C.M.; Wei, F. Permselective Graphene Oxide Membrane for Highly Stable and Anti-Self-Discharge Lithium-Sulfur Batteries. ACS Nano 2015, 9, 3002-3011.

(60) Rosenman, A.; Elazari, R.; Salitra, G.; Markevich, E.; Aurbach, D.; Garsuch, A. The Effect of Interactions and Reduction Products of LiNO3, the Anti-Shuttle Agent, in Li-S Battery Systems. J. Electrochem. Soc. 2015, 162, A470-A473.

(61) Strubel, P.; Thieme, S.; Weller, C.; Althues, H.; Kaskel, S. Insights into the redistribution of sulfur species during cycling in lithium-sulfur batteries using physisorption methods. Nano Energy $2017,34,437-441$

(62) Liu, M.; Visco, S. J.; De Jonghe, L. C. Novel Solid Redox Polymerization Electrodes. J. Electrochem. Soc. 1991, 138, 1896-1901.

(63) Eftekhari, A. Energy efficiency: a critically important but neglected factor in battery research. Sustainable Energy Fuels 2017, 1, 2053-2060.

(64) Frisch, M. J.; Trucks, G. W.; Schlegel, H. B.; Scuseria, G. E.; Robb, M. A.; Cheeseman, J. R.; Scalmani, G.; Barone, V.; Mennucc, B.; Petersson, G. A.; Nakatsuji, H.; Caricato, M.; Li, X.; Hratchian, H. P.; Izmaylov, A. F.; Bloino, J.; Zheng, G.; Sonnenberg, J. L.; Hada, M.; Ehara, M.; Toyota, K.; Fukuda, R.; Hasegawa, J.; Ishida, M.; Nakajima, T.; Honda, Y.; Kitao, O.; Nakai, H.; Vreven, T.; Montgomery, J. A., Jr.; Peralta, J. E.; Ogliaro, F.; Bearpark, M.; Heyd, J. J.; Brothers, E.; Kudin, K. N.; Staroverov, V. N.; Keith, T.; Kobayashi, R.; Normand, J.; Raghavachari, K.; Rendell, A.; Burant, J.

C.; Iyengar, S. S.; Tomasi, J.; Cossi, M.; Rega, N.; Millam, J. M.; 
Klene, M.; Knox, J. E.; Cross, J. B.; Bakken, V.; Adamo, C.; Jaramillo, J.; Gomperts, R.; Stratmann, R. E.; Yazyev, O.; Austin, A. J.; Cammi, R.; Pomelli, C.; Ochterski, J. W.; Martin, R. L.; Morokuma, K.; Zakrzewski, V. G.; Voth, G. A.; Salvador, P.; Dannenberg, J. J.; Dapprich, S.; Daniels, A. D.; Farkas, O.; Foresman, J. B.; Ortiz, J. V.; Cioslowski, J.; Fox, D. J. Gaussian 09, Revision B.01; Gaussian, Inc.: Wallingford CT, 2010.

(65) Pang, Q.; Nazar, L. F. Long-Life and High-Areal-Capacity Li-S Batteries Enabled by a Light-Weight Polar Host with Intrinsic Polysulfide Adsorption. ACS Nano 2016, 10, 4111-4118. 
2018-06-06

\section{A universal strategy to prepare} sulfur-containing polymer composites with desired morphologies for pÿlithium"sulfur batteries

\section{Zeng, Shao-Zhong}

American Chemical Society

Shao-Zhong Zeng, Xierong Zeng, Wenxuan Tu, et al., A universal strategy to prepare pÿsulfur-containing polymer composites with desired morphologies for lithium"sulfur batteries. ACS Applied Materials and Interfaces, 2018, Volume 10, Issue 26, pp. $22002-22012$ https://doi.org/10.1021/acsami.8b03611 Downloaded from Cranfield Library Services E-Repository 